\title{
Fracture Failure Characteristics of Jointed Sandstone under Uniaxial Compression
}

\author{
Ronghua Su $(\mathbb{D})$ and Xiaolin Liu \\ School of Mechanics and Engineering, Liaoning Technical University, Fuxin 123000, China \\ Correspondence should be addressed to Ronghua Su; suronghua@lntu.edu.cn
}

Received 16 September 2020; Revised 24 October 2020; Accepted 2 November 2020; Published 1 December 2020

Academic Editor: Yanlin Zhao

Copyright ( 2020 Ronghua Su and Xiaolin Liu. This is an open access article distributed under the Creative Commons Attribution License, which permits unrestricted use, distribution, and reproduction in any medium, provided the original work is properly cited.

\begin{abstract}
Jointed rocks are ubiquitous in the complex environments (coupled heat and moisture conditions) encountered in deep underground mining. To investigate the influence of the joint locations on the strength, deformation, and fracture failure characteristics of the jointed sandstone, uniaxial compression tests were carried out for sandstone specimens in a natural moisture state and with a preexisting joint in different locations. The entire test process was recorded by a dynamic strain acquisition system and digital speckle observation equipment. The results show that the peak strength weakening of the jointed sandstone was different with different joint positions. The residual strength and lateral deformation of the jointed sandstone were affected by the location of the joint. The joint locations dominated the evolution of the fractures in the sandstone and influenced the failure mode. The fracture evolution in sandstone with a joint in the middle was characterized by the closure of the fractures away from the starting position and was finally destroyed by the combination of shearing and splitting. The evolution of fractures in the sandstone with a joint at the bottom was stopped on the other side, which was eventually sheared across the joint. Besides, based on fractal theory, the fracture distribution on the specimen surface was analysed at certain points (first appearance of fracture, peak point) and the final destruction state during the fracture evolution. The fractal dimension was obtained, which further characterizes the fracture evolution and failure of sandstone with a joint at different locations.
\end{abstract}

\section{Introduction}

As mining engineering develops deeper, the rock exists in more complex geological environments with high temperatures, high stresses, and high permeability. The rock is randomly endowed with joints and cracks other defects, which aggravates the fracture development of the rock and has an essential impact on the destabilization of the roadway. Therefore, the distribution of joints is an important factor to the mechanical and fracture failure characteristics of jointed rock.

In recent years, professionals and scholars have studied the mechanical properties of rock with defects such as joints, fissures, and holes $[1,2]$ by theoretical analysis, experiments, and numerical simulation [3-5] and achieved important results [6-9]. In laboratory tests, considering the loading mode [10], it mainly includes the uniaxial tensile test, uniaxial compression test, triaxial test, and shear test. The external environment is described by factors such as temperature, water content, and permeability $[11,12]$. In terms of the internal structure of the rock, the main parameters include joint surface roughness, joint dip, and joint spacing. A rough joint model was established to study the strength and elastic modulus of jointed rock masses under different loads [13]. The deformation and strength characteristics of rock were also studied under cyclic uniaxial loading [14]. The dynamic characteristics of rock masses with different dip angles were considered in cyclic triaxial tests at different frequencies, and the results showed that the volume strain and axial strain of the rock mass increased with increasing frequency [15]. Under cyclic loading conditions, the fatigue characteristics of the jointed rock were analysed for different joint geometries [16]. Through shear testing, the influence of the number of cycles on the shear strength of jointed rock was studied under cyclic loading [17-19], and the type of rock and joint 
roughness and size have a certain influence on the shear strength of the rock mass [20-22]. The deformation and strength characteristics of rock with different forms of joints were obtained by tensile tests and uniaxial compression tests $[23,24]$. In underground engineering, the existence of water weakens the mechanical properties of the rock mass; thus, the shear strength of jointed rock mass has been studied for different permeabilities $[25,26]$. The permeability laws under uniaxial compressive and triaxial tests were compared, and the influence of permeability on confining pressure was analysed [27]. In the past, a large number of studies have been carried out on the influence of the number of joint groups [28-31], degree of joint penetration [32-34], joint surface roughness and anisotropy [35-37], joint dip angle and spacing [38-40], and joint geometric characteristics $[41,42]$. With the increase of the joint dip angle, the peak strength shows a " $U$ " shape. The failure mode of jointed rock is more complex with a $30^{\circ}$ dip angle [43-45]. Wasantha et al. [46] argued that the location of partially spanning joints had an impact on compressive strength but did not indicate the influence of penetration joint locations on the fracture evolution characteristics of rock masses.

In the study of joints, advanced techniques have been applied. The computed tomography (CT) scanning can be used to further obtain the microstructure and overall threedimensional model of jointed rock [47]. A digital speckle pattern was used to monitor the deformation and failure of marble containing a triangular fault under biaxial compression, the fracture evolution law was obtained, and an index to serve as a failure precursor was determined [48]. The whole process of jointed rock was monitored utilizing digital speckle observation; then, the fracture mode of the joint rock was obtained under uniaxial compression [49].

The fractal theory has important practical applications and can explain the complex rock fracture evolution and destruction phenomena well [50-53]. However, the effect of the joint location on the fracture development and failure characteristics of sandstone has rarely been studied.

Therefore, in this paper, considering the locations of joints, uniaxial compression tests were carried out on the jointed rock with a $30^{\circ}$ dip angle under a natural waterbearing state. The whole test progress was recorded by a dynamic strain test system and digital speckle correlation equipment. The strength, deformation, and fracture failure characteristics of this sandstone were studied considering different joint locations. Based on fractal theory, the fracture evolution and failure characteristics of the jointed sandstone were analysed.

\section{Uniaxial Compression Tests of Jointed Sandstone}

2.1. Sample Preparation and Test Equipment. To study the fracture failure characteristics of jointed sandstone under uniaxial compression, the moisture content and temperature of each rock sample including a single joint are kept constant. We designed three types of joint locations, resulting in intact sandstone samples, sandstone samples with a joint in the middle, and a joint plane at the bottom. The $50 \times 50 \times 100$ $\mathrm{mm}^{3}$ standard rectangular specimens were made of sandstone blocks without obvious cracks. The nonparallelism of the two ends was not more than $0.05 \mathrm{~mm}$. The fracture surfaces of the sandstone specimens with a $30^{\circ}$ joint dip angle were assembled to have a certain roughness and undulation. The laboratory temperature was controlled at $27^{\circ} \mathrm{C}$, and the sandstone samples were in a natural moisture state. Thus, three groups of experiments were designed, as shown in Table 1. The schematic diagrams of the sandstone specimens with joint planes are shown in Figure 1.

The uniaxial compression test device and its schematic diagram for jointed sandstone are shown in Figure 2. In this test, uniaxial compression tests were performed by a YEW2000 rock electrohydraulic servo tester. The lateral and axial strains of the specimens were measured and recorded by a DH-8923 dynamic strain collector; in addition, the rock fracture development and failure processes were monitored and recorded using CCD camera equipment.

\subsection{Test Process}

(1) First, speckles were added and strain gauges were set on the surface of the sandstone specimens. White paint and speckles were applied on the smooth surface. Lateral and axial strain gauges were attached to the other smooth surfaces with no visible cracks. After that, the specimen was placed in the middle of the test bench

(2) Second, the strain gauge wires were connected to the dynamic strain measurement instrument by a halfbridge. The maximum acquisition frequency and the sampling frequency of the dynamic strain acquisition were set to $100 \mathrm{kHz} / \mathrm{s}$ and $5 \mathrm{~Hz} / \mathrm{s}$, respectively

(3) Third, the CCD camera was installed and connected to the computer with relevant software. Next, the focus and the light were adjusted. The resolution of the camera used was $1234 \times 1245$ pixels, and its acquisition speed was $3.52 \mathrm{fps}$. The field of view was set to $50 \times 100 \mathrm{~mm}^{2}$, which was used to monitor the development of global fractures on the rock surface

(4) Finally, the YEW-2000 rock electrohydraulic servo tester was used for displacement loading, and its loading rate was $0.005 \mathrm{~mm} / \mathrm{min}$. The loading equipment, digital speckle equipment, and dynamic strain test system were set to collect data simultaneously

\section{Mechanical Characteristics of Jointed Sandstone}

3.1. Strength Characteristics of Jointed Sandstone. Figure 3 shows the axial strain-stress curves of the representative specimens from the three groups: S1-2, S2-3, and S3-2. The peak strength and the residual strength represent the maximum resistance of the rock to failure and the minimum resistance after macroscopic failure, respectively. The peak strength $\sigma_{\max }$ of the rock can be calculated using the following formula: 
TABLE 1: Specimen preparation scheme.

Group
number
S1-1
S1-2
S1 $\quad$ S1-3
S1-4

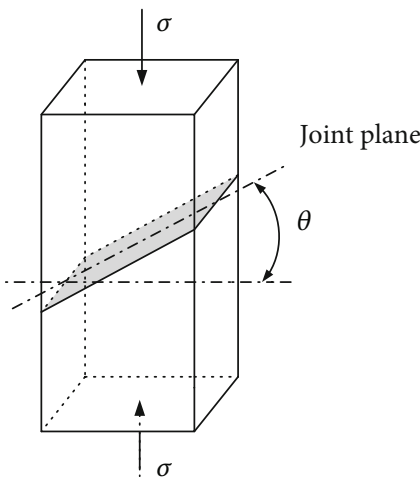

(a)

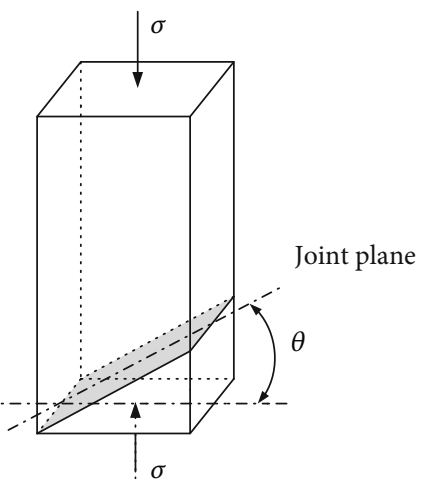

(b)

Figure 1: Schematic diagram of jointed sandstone specimens under uniaxial compression.

$$
\sigma_{\max }=\frac{F_{\max }}{A}
$$

where $F_{\max }$ is the maximum load at specimen failure and $A$ is the cross-sectional area of the specimen.

For jointed rock, the rock residual strength is based on the Hoek-Brown criterion [54] as follows:

$$
\sigma_{1}=\sigma_{3}+\sigma_{c}\left(\frac{m_{b} \sigma_{3}}{\sigma_{c}+s}\right)^{0.5}
$$

where $\sigma_{1}$ and $\sigma_{3}$ characterize the maximum and minimum principal stresses at failure, respectively. $m_{b}$ is the HoekBrown constant of the rock. $s$ is the material constant related to the rock, reflecting the rock fragmentation degree, and its value ranges from 0 to $1 . \sigma_{c}$ is the peak strength of the intact rock. In this test, $\sigma_{3}=0$, the residual strength $\sigma_{\mathrm{r}}$ of the rock mass can be obtained using

$$
\sigma_{\mathrm{r}}=\sigma_{1}=\sigma_{c} s^{0.5}=\sqrt{s} \sigma_{c} .
$$

If the rock is in a natural water state and not disturbed, the material constant $s$ is calculated by

$$
s=\exp \left(\frac{\mathrm{GSI}-100}{9}\right),
$$

where GSI (geological strength index) is obtained from the results and GSI classification. The calculated peak strength and residual strength results of the three specimens are summarized in Table 2. 


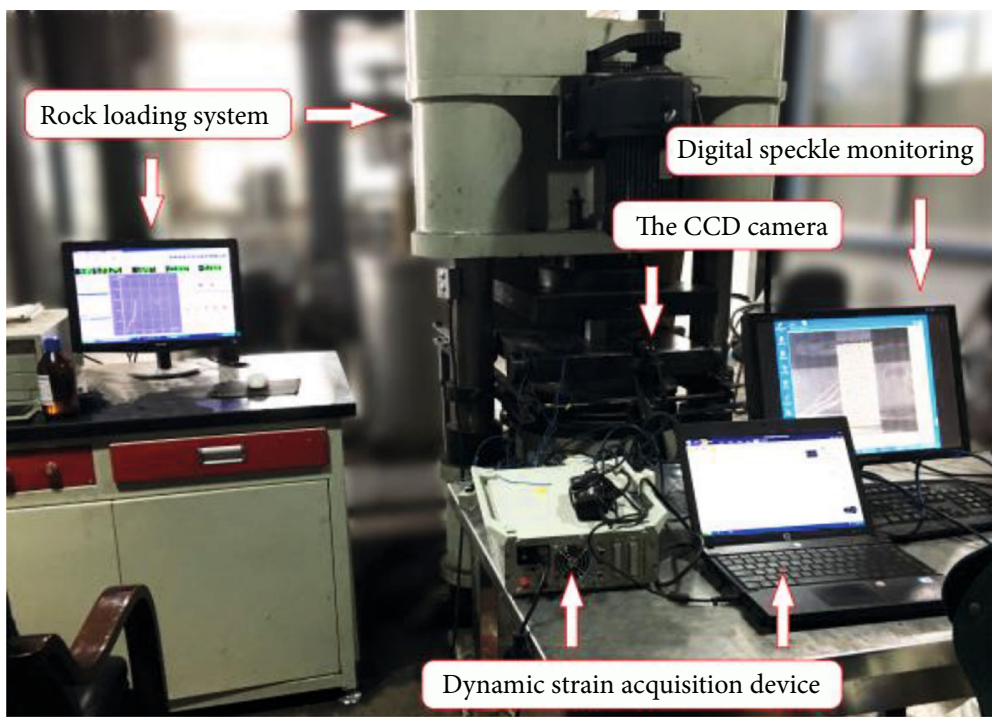

(a) Test system

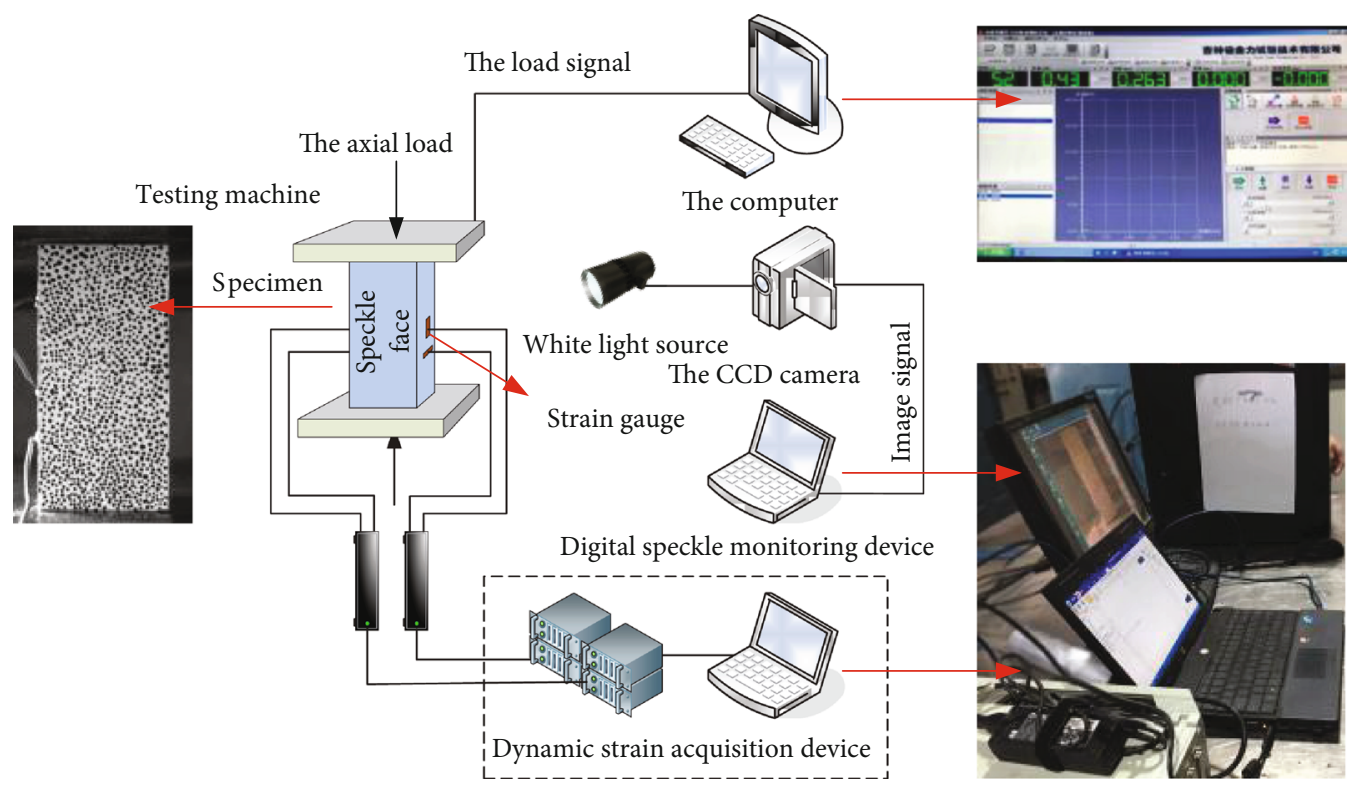

(b) Schematic diagram

Figure 2: Test system and its schematic diagram.

The peak strength of specimens S2-3 and S3-2 was reduced by $22.67 \%$ and $13.64 \%$, respectively, relative to that of specimen S1-2. The peak strength of specimen S2-3 was reduced by $9.03 \%$ compared with that of specimen S3-2. Therefore, the peak strength of the jointed sandstone was significantly lower than that of the intact sandstone. Also, the position of the joint plane had a certain influence on the peak strength of the sandstone. When the joint plane is in the middle of the sandstone, the compressive stress is significantly reduced, and the joint plane plays a more crucial role in the strength of the sandstone.

Since the residual strength is provided by the internal friction at the fracture surface, the higher the residual stress, the more fracture surfaces the sandstone specimen will have. The residual strength in the sandstone with a joint plane was higher than that of the intact sandstone, indicating that the interior of the jointed rock had more fracture planes under uniaxial compression. The residual strength of S2-3 was greater than that of S3-2, indicating that the residual stress of sandstone with a joint plane in the middle was significantly higher than that of sandstone with a joint plane at the bottom; that is, the sandstone with a joint surface in the middle will have more fracture surfaces.

3.2. Deformation Characteristics of Jointed Sandstone. The axial-lateral strain curves of the jointed sandstone under uniaxial compression are shown in Figure 4. Combined with Figure 3, the deformation results of jointed sandstone were analysed, and it was found that there were still four stages in the deformation curves: the shrinkage compaction stage, linear elastic stage, yield stage, and fracture stage. 


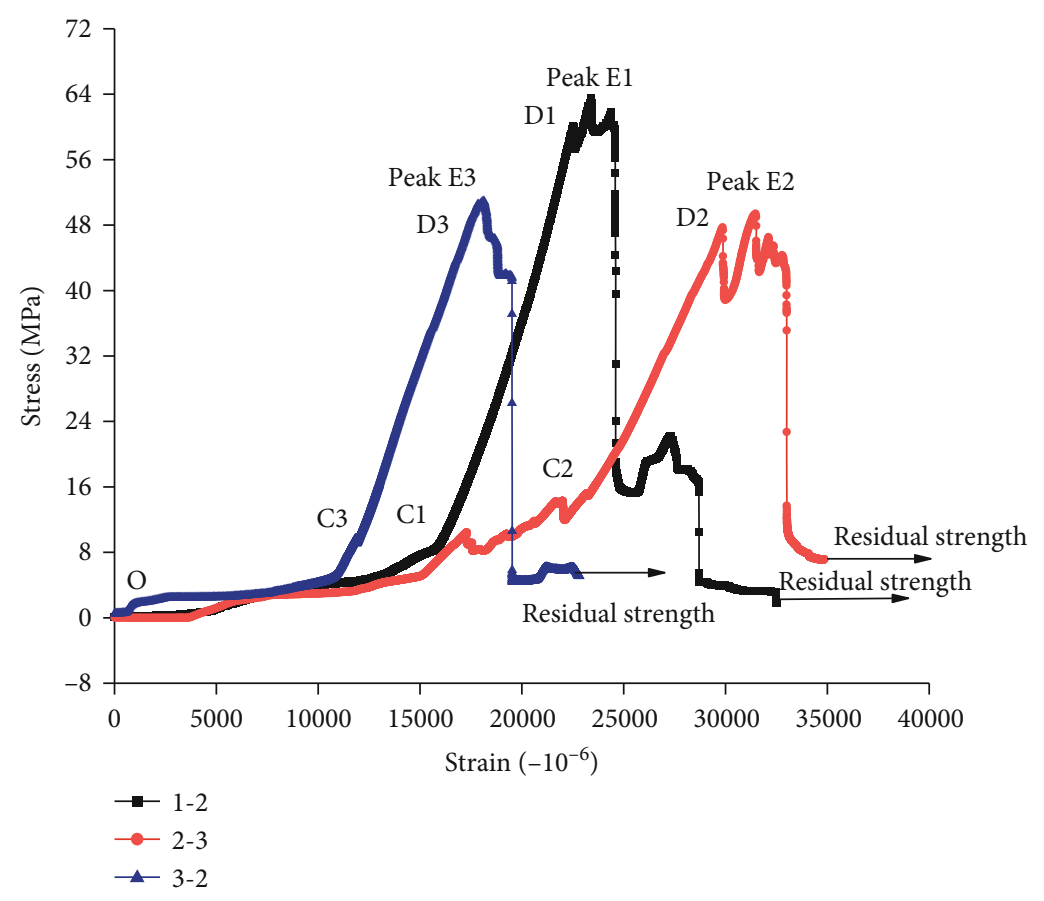

FIGURE 3: The stress and axial strain curves of the representative sandstone specimens.

TABLE 2: The peak and residual strengths of the representative sandstone specimens.

\begin{tabular}{lcc}
\hline $\begin{array}{l}\text { Specimen } \\
\text { number }\end{array}$ & Peak strength $(\mathrm{MPa})$ & Residual strength (MPa) \\
\hline S1-2 & 61.28 & 3.22 \\
S2-3 & 47.39 & 7.14 \\
S3-2 & 52.92 & 5.09 \\
\hline
\end{tabular}

(1) The shrinkage and compaction stages of S1-2, S2-3, and S3-2 correspond to the stages OC1, OC2, and OC3 of the stress-strain curves, respectively. As shown in Figure 4, specimens S1-2 and S3-2 underwent a small lateral expansion before negative Poisson's ratio effect (negative Poisson's ratio effect refers to the phenomenon that rock shrinks laterally under compression). The internal structure of the specimen was adjusted during the initial loading, so the short duration of Poisson's ratio effect was negligible. However, negative Poisson's ratio effect of specimen S2-3 appeared at the origin of the corresponding plot and continued until the linear elastic stage. Then, it disappeared, and lateral expansion occurred. These results show that the location of the joint plane in the middle of the specimen caused shrinkage in this stage, which made the equilibrium stabilization process longer and the cracking development more complicated

(2) The linear elastic stages of S1-2, S2-3, and S3-2 correspond to the stages C1D1, C2D2, and C3D 3 on the stress-strain curves. The slope of this stage on the stress-strain curves, also known as the deformation modulus, is represented by $k_{\mathrm{C} 1 \mathrm{D} 1}, k_{\mathrm{C} 2 \mathrm{D} 2}$, and $k_{\mathrm{C} 3 \mathrm{D} 3}$, respectively. $k_{\mathrm{C} 2 \mathrm{D} 2}<k_{\mathrm{C} 3 \mathrm{D} 3}<k_{\mathrm{C} 1 \mathrm{D} 1}$ indicated that the joint reduced the ability of the sandstone to resist elastic deformation. And the location of the joint had a significant effect on the ability of the sandstone to resist elastic deformation. The slope of this stage on the lateral-axial strain curves, also known as Poisson's ratio, is represented by $v_{\mathrm{C} 1 \mathrm{D} 1}, v_{\mathrm{C} 2 \mathrm{D} 2}$, and $v_{\mathrm{C} 3 \mathrm{D} 3}$. $v_{\mathrm{C} 1 \mathrm{D} 1}<v_{\mathrm{C} 3 \mathrm{D} 3}<v_{\mathrm{C} 2 \mathrm{D} 2}$ indicated that the location of the joint had a significant influence on the lateral deformation.

(3) In the yield stage, the deformation curve of S1-2 exhibited a small stress drop first, and then, the failure occurred. The stress-axial strain curve of specimen S2-3 showed several steep stress drops, followed by a small period of plastic flow before destruction. In contrast, specimen S3-2 was destroyed immediately, without a significant yield phase. As shown in Figure 4, the lateral strains at the peak of specimens S1-2, S2-3, and S3-2 were $2023.38 \times 10^{-6}, 1959.29 \times 10^{-6}$, and $2494.07 \times 10^{-6}$, respectively. Compared with that of the intact sandstone, the lateral strain of the sandstone with a joint at the bottom was lower, and that of the sandstone with a joint in the middle was more pronounced. In general, these results show that the lateral deformation of the sandstone was related not only to the presence or absence of a joint plane but also to its location

(4) In the postrupture phase (after peak E), after a sudden drop in the S1-2 curve, there was a short 


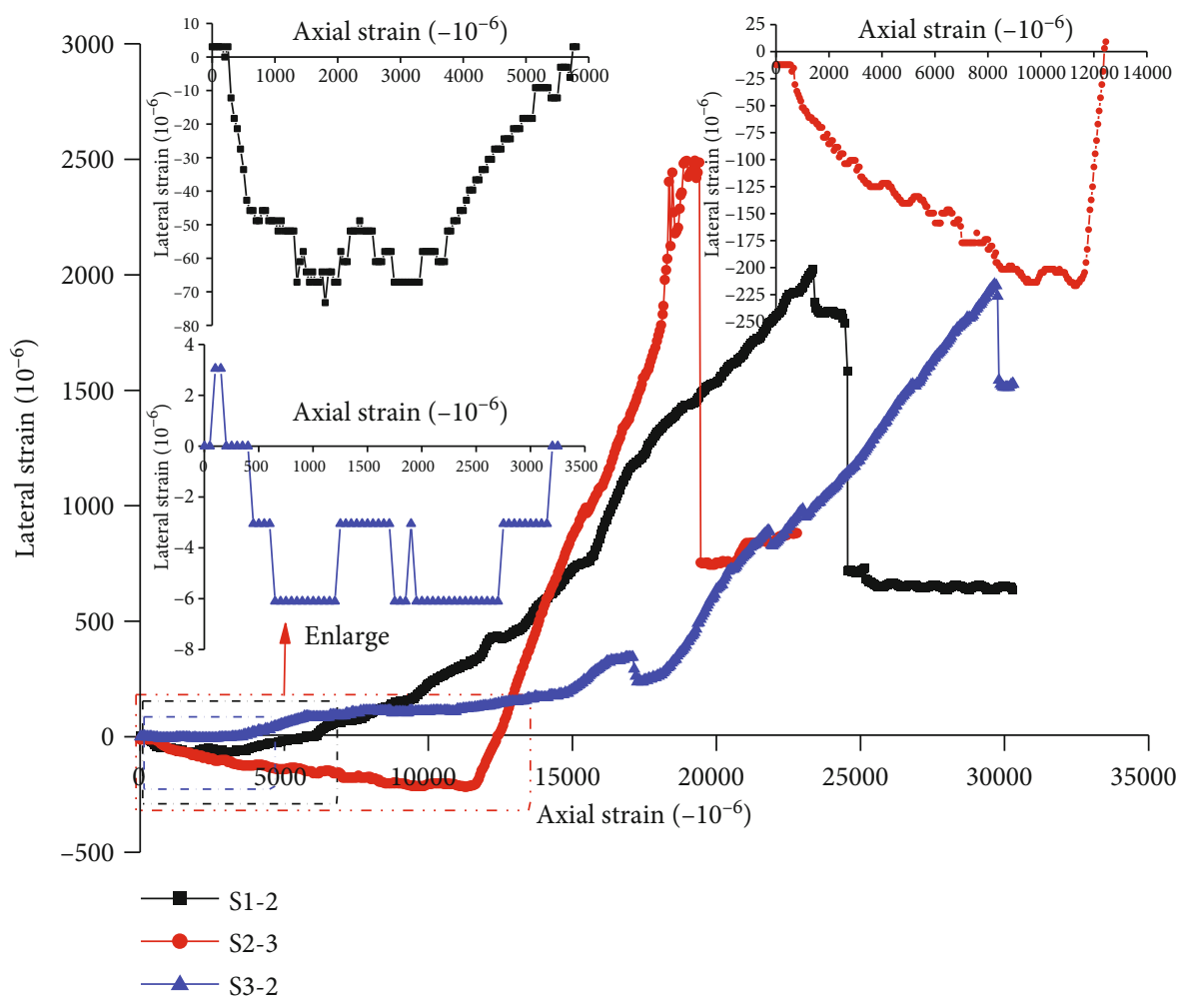

FiguRE 4: Lateral and axial strain curves of the representative sandstone specimens.

plastic flow phase after the brittle failure of the specimen occurred. The lateral and axial strain curves of specimen S2-3 had many small fluctuations after weakening. The axial strain curves of specimen S3-2 had stepped down, but its lateral strain curves had small fluctuations

\section{Damage Characteristics of Jointed Sandstone}

4.1. Fracture Evolution of Jointed Sandstone. Figure 5 shows the development of surface fractures in specimen S1-2. Combined with Figure 3, Figure 5 shows that at the extreme value D1 of the stress-strain curve, a crack was generated at the upper end of specimen S1-2 and started to expand in the axial direction. At the peak point of the stress-strain curve, a new splitting occurred due to the local shear failure of the specimen. A shear surface was created at the upper end of the sandstone, causing sandstone splitting and leading to destabilization and destruction of the sandstone far from the main body. Then, the original elastic strain energy was recovered. At this time, two small stress drops occurred near the peak of the stress-strain curve. Specimen S1-2 was mainly damaged by a combination of splitting and local shear failure.

Figure 6 illustrates the development of surface fractures in specimen S2-3. According to the analysis in Figure 3, there were two obvious increases and decreases in the stage OD2, resulting in three extreme points. When the first extreme point occurred, horizontal cracks were created along the joint. At the second extreme point, the horizontal crack of the specimen was closed, and an axial crack developed. At the third extreme point D2, the second obvious splitting surface formed. At the peak point, the splitting crack tore along the horizontal direction. After the peak, there were many small fluctuations in the curve, the specimen's bearing capacity was weakened, and destabilization damage occurred. Overall, the analysis revealed the characteristics of crack development in specimen S2-3. The fracturing started from the joint and developed along the horizontal direction, and then, comminuted spalling occurred on the rock surface where the joint surface was located. The lateral crack of the sandstone was compacted so that the sandstone specimen formed two parts, and on the right side, a pressure rod was formed that ultimately split and destroyed the sandstone. The yielding phase of the stress-strain curve was prolonged, and the sandstone with a joint plane in the middle tended to exhibit ductile failure.

Figure 7 shows the fracture evolution of specimen S3-2. In combination with the analysis in Figure 3, Figure 7 shows no obvious cracking on the surface of the specimen before the C3 point on the stress-axial strain curve. At the C3D3 stage, spalling started to occur at the specimen's joint surface, with the first crack at the bottom left of the specimen's surface. By the middle of the loading period, the rock sample was cracked and spalled at the joint plane. At the peak, a shear fracture formed across the joint at an angle of approximately $55^{\circ}$, with the main shear surface terminating on the other side of the rock sample. Crushing spalling occurred near the shear surface of the rock sample. It was found that the fracture started at the joint position and ended at the right side of specimen S3-2. In short, the specimens were destroyed via shear failure, which was relatively simple. 


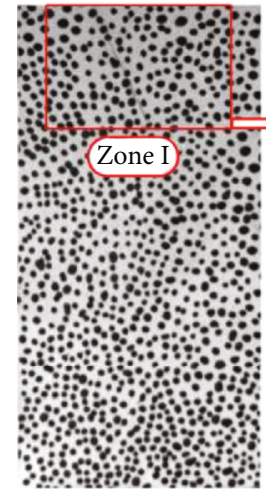

(a) Crack initiation
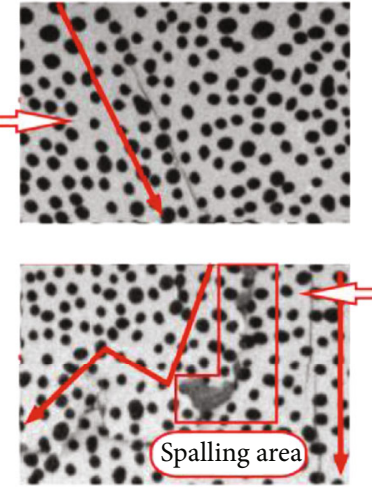

(b) Local enlarged drawing

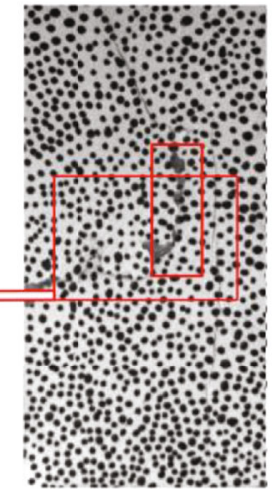

(c) Fracture development

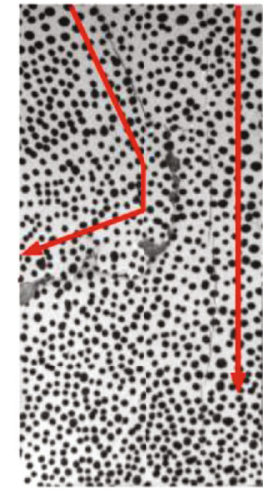

(d) Final failure mode

FIgURE 5: The surface fracture evolution process of specimen S1-2.

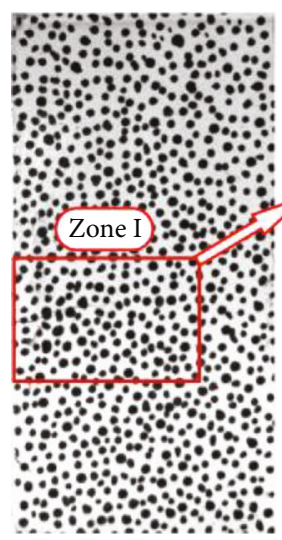

(a) Crack initiation

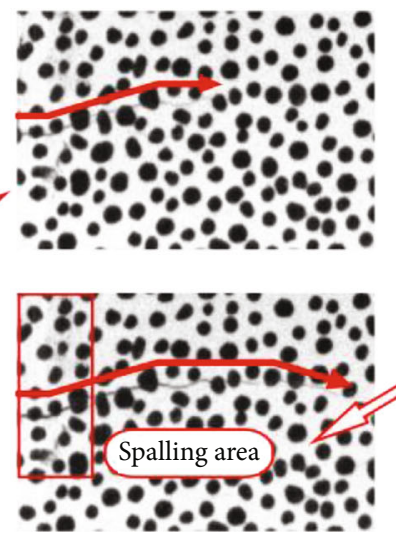

(b) Local enlarged drawing

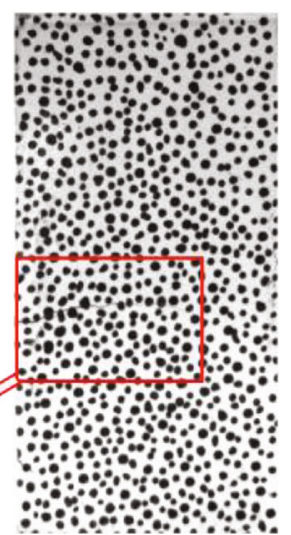

(c) Fracture development

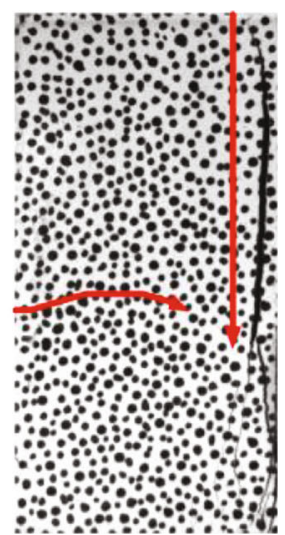

(d) Final failure mode

FIgURE 6: The surface fracture evolution process of specimen S2-3.

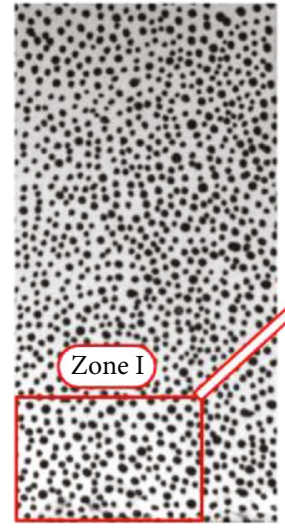

(a) Crack initiation

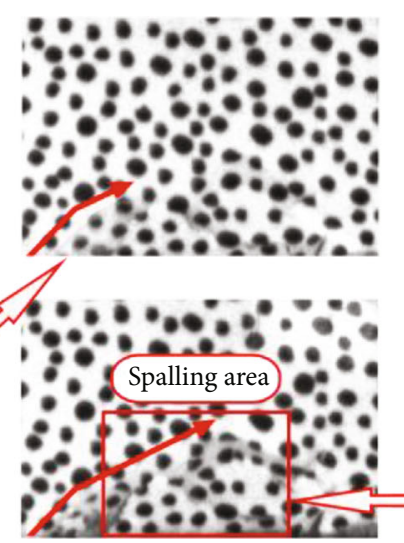

(b) Local enlarged drawing

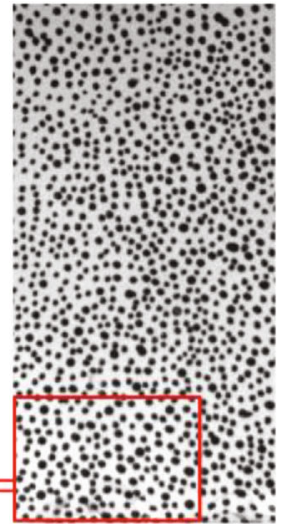

(c) Fracture development

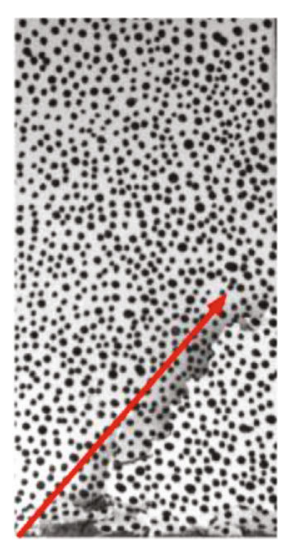

(d) Final failure mode

FIgURE 7: The surface fracture evolution process of specimen S3-2.

In summary, the fracture evolution of sandstone was influenced and controlled by joints with a $30^{\circ}$ dip and its location. That is, the fracture began in the position of the joint and developed far from the initial, with obvious spalling near the joint. The location of the joint plane significantly influenced the form of sandstone failure. The sandstone specimen with a joint in the middle was damaged by a combination of shear and cleavage failure across the joint. However, the sandstone with a joint plane in the bottom was damaged by shear failure across the joint.

4.2. Fracture Failure Characteristics Monitored by Digital Speckle Equipment. The whole test of jointed sandstone was monitored by digital speckle equipment. Based on the above analysis, the moment of initial fracture and the peak point were two key points during the fracture evolution, and the 


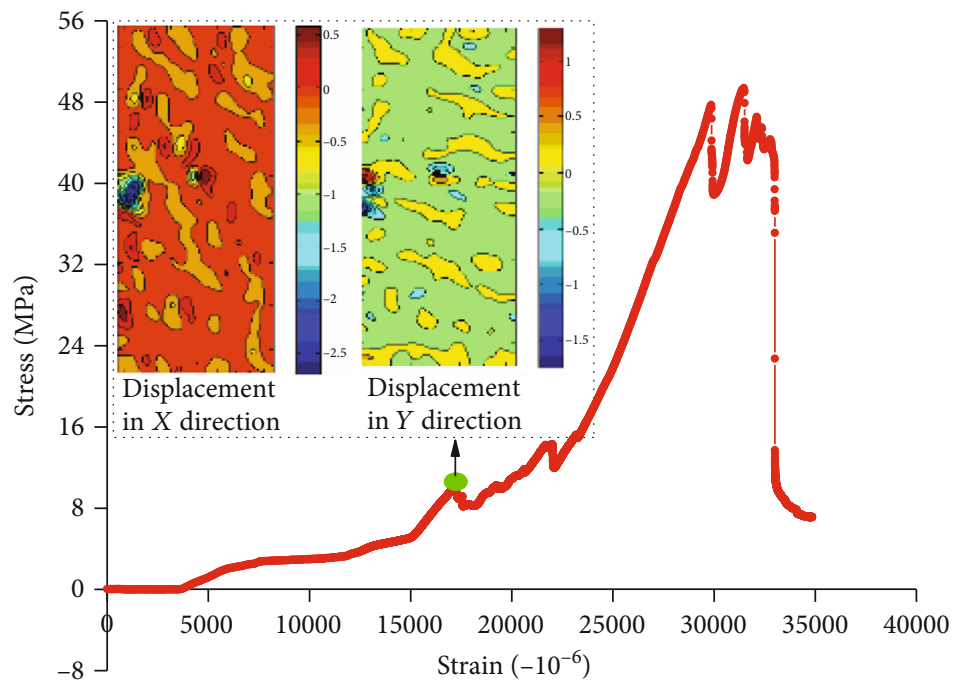

(a) At the first fracture

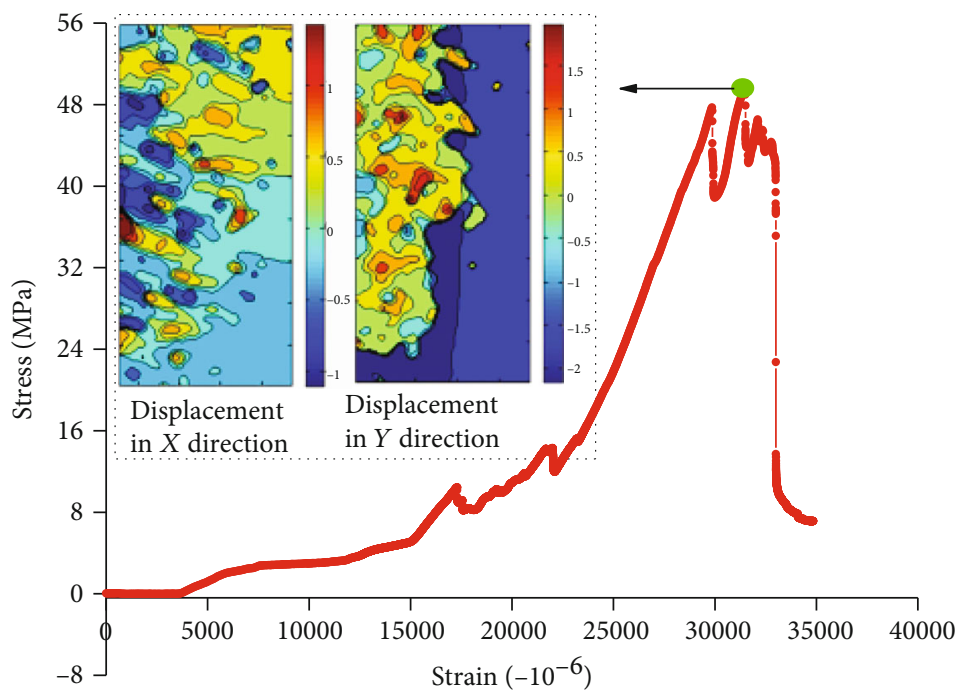

(b) At the peak point

FIgURE 8: Displacement of specimen S2-3 by DSCM.

speckle results of the jointed sandstone were analysed at these two critical moments. Thus, the displacement observations of specimens S2-3 and S3-2 are presented in Figures 8 and 9, respectively.

As shown in Figure 8, when the fracture first appeared, the maximum displacement was on the left side of the central part of the model in the $X$-direction displacement diagram, from which the fracture began to develop. At the peak stress, the maximum displacement (red area) was in the middle of the model on the left side, and the horizontal direction was banded. By analysing the $Y$-direction displacement diagram, it was found that the displacement concentrated on the left side of the specimen and in bands on the right side. The above phenomenon was due to the pressure and tight closure of the horizontal fissure on the left side and the formation of a pressure bar on the right side of the specimen, resulting in pressure damage. The failure mode of the sandstone specimen with the joint surface in the middle was a combination of shear across the joint and splitting failure.
As shown in Figure 9, when specimen S3-2 first appeared to crack, the displacement reached the maximum at the left bottom of the model, and the fracture began to develop in this area. At the peak point, the $X$-direction displacement field presented a shear band distribution, and the deformation concentration phenomenon appeared. A steeply undulating shear surface was formed at the location of the joint. The $Y$-direction displacement formed a concentrated band at the lower corner of the model, and a shear band was formed along with the location of the joint. Generally, in the elastic stage, there was a local stress concentration in the deformation field. In the second stage, the local deformation field started to expand into a band. At the peak point, the specimen was penetrated by the fracture completely. The destruction of the sandstone specimen with the joint surface at the bottom was in the form of shear failure across the joint surface. The sandstone specimens were damaged due to shearing across the joint, and the DSCM observations were consistent with the destruction state of the sandstone. 


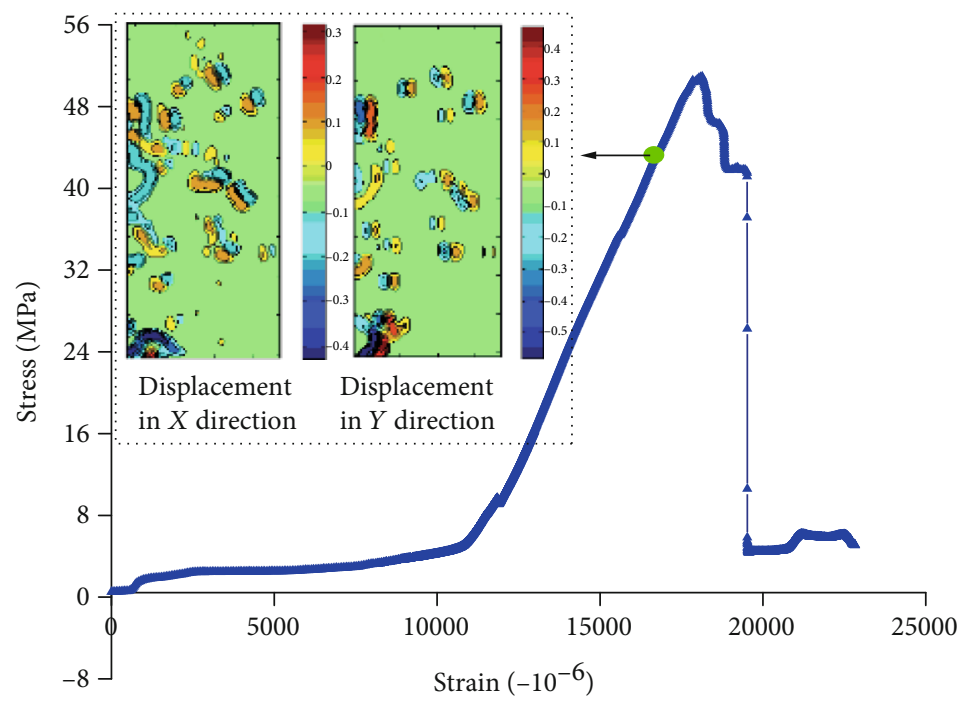

(a) At the first fracture

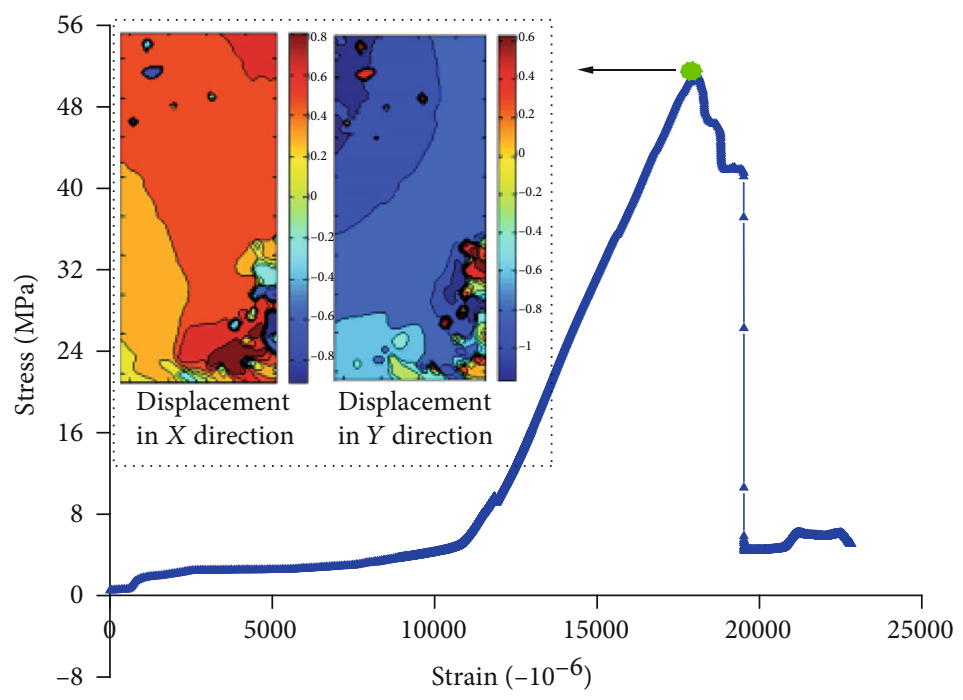

(b) At the peak point

FIGURE 9: Displacement of specimen S3-2 by DSCM.

4.3. Fractal Characteristics of the Surface Fracture. According to the above test results, the evolution of the fractures in the sandstone containing a joint in the middle was characterized by the fact that the fissures started from the joint location and that the area near the joint was prone to pressurized closure while the fissures far from the joint expanded and penetrated. For the sandstone with a joint at the bottom, the fracture began at the joint, forming a shear plane that started at the lower and ended at the right side of the specimen. The surface fracture distribution characteristics were quantitatively analysed at key moments (the moment of initial fracture and at the peak point) during the evolution of the three groups of sandstones using box dimension numbers. The fractal box dimension $d$ is defined as follows:

$$
d=\lim _{r \rightarrow 0} \frac{\log N(r)}{\log (1 / r)}
$$

where $N(r)$ represents the number of square boxes with side length $r$; the smaller $r$ is, the larger $N(r)$ is. Then, three groups of sandstone surfaces were divided into boxes, and the $N(r)$ value was counted. When $r \rightarrow 0$, the corresponding $N(r)$ change is the box number, which reflects the complexity of the fracture distribution and development.

Figure 10 shows the box dimension of fracture distribution in zone I (Figures 5-7) for specimens S1-2, S2-3, and S3-2. The box dimensions of the surface crack distribution are $1.08,1.05$, and 1.09 when cracks appeared for the first time in S1-2, S2-3, and S3-2, respectively. However, the box dimensions of S1-2, S2-3, and S3-2 were 1.15, 1.01, and 1.08, respectively. The fractal dimension of S1-2 increased, which indicated that the initial crack of the specimen expanded. The fractal dimension of S2-3 decreased, which indicated that the initial fracture closed. The fractal dimension of S3-2 decreased slightly, and the cracks closed. 


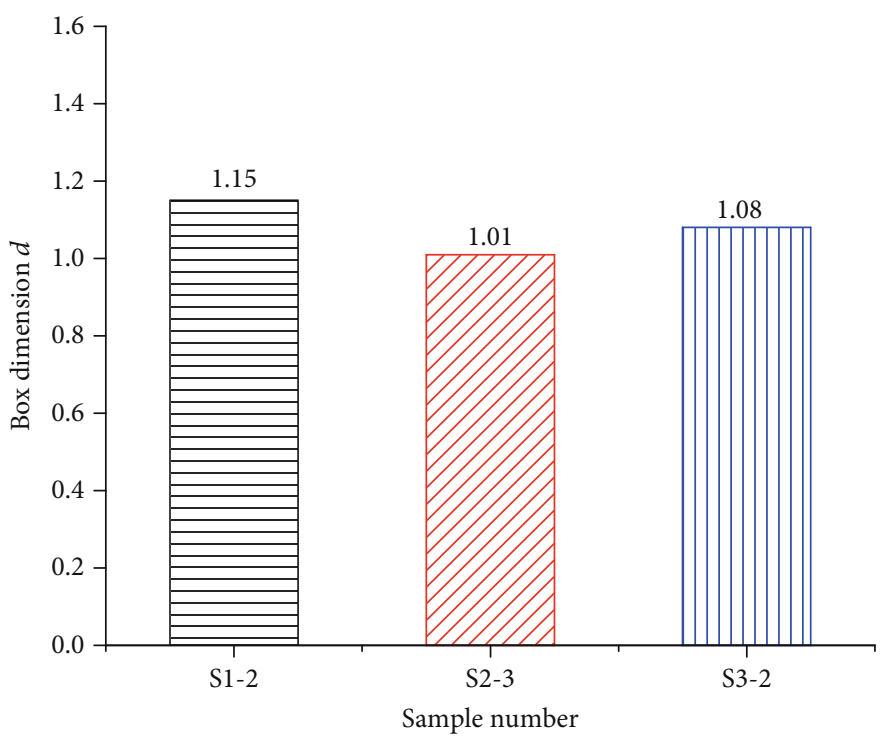

(a) At the first fracture

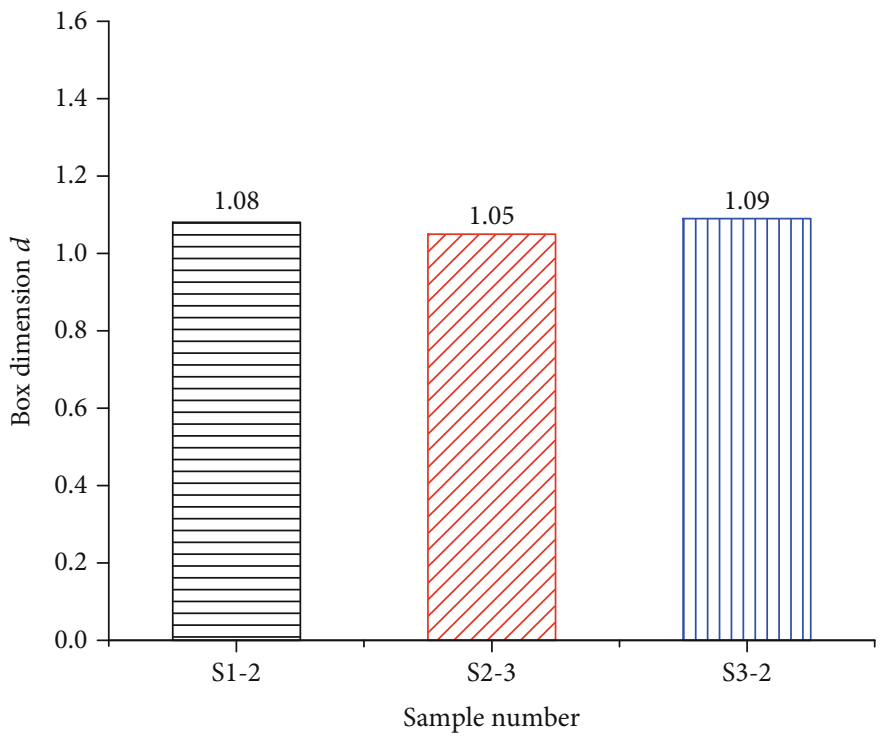

(b) At the peak point

FIGURE 10: The fractal dimension of the sandstone surface fracture distribution in zone I.

Moreover, Figure 11 shows the box dimension of the final global fracture of the specimens. The data were fitted using the least-square method to count the fractal dimensions. The fitting formula is as follows:

$$
y=I+B 1 * x,
$$

where the independent variable $x$ is represented by $\log r$ and the dependent variable $y$ is represented by $\log N(r) . B 1$ is the slope of the fitting line, the box dimension $d=-B 1, I$ is the constant, and the fitting degree $R^{2}>0.99$. The box dimension $d$ of S1-2, S2-3, and S3-2 were 1.337, 1.402, and 1.306, indicating that the surface cracks became increasingly complex with increasing load. Considering the analysis of Figures 68 , when the sandstone specimen S1-2 cracked for the first time, the surface cracks began to produce shear cracks from the upper end and finally expanded and connected along the initial fracture. During the loading process of specimen S2-3, the first crack was initiated at the joint and then closed, and then, splitting occurred away from that initiation area, with a complex distribution of cracks. The crack of specimen S3-2 started at the location of the joint and then closed, shear damage occurred across the joint, and the crack penetrated through the rock.

Generally, the fractal dimension $d$ of the sandstone specimen with a joint in the middle was the largest, and its failure form was the most complex and thus more likely to result in a hazardous situation. The dimension of the sandstone specimen with a joint surface at the bottom was lower than that of the intact sandstone, and the failure mode was 


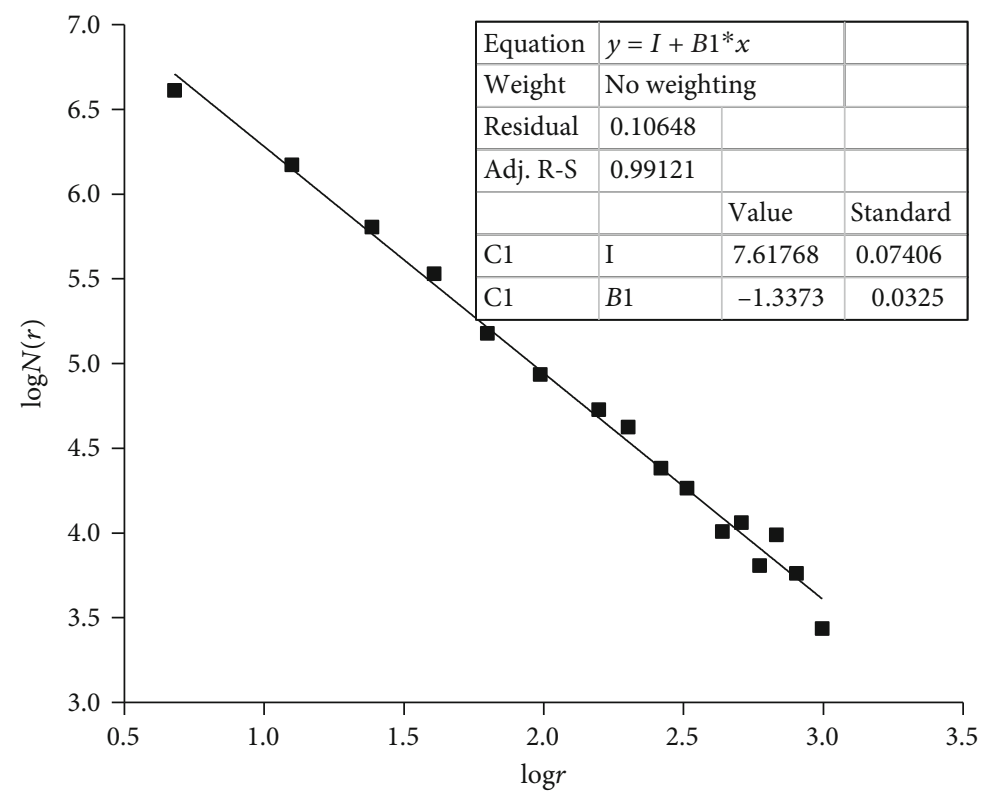

(a) $\mathrm{S} 1-2$

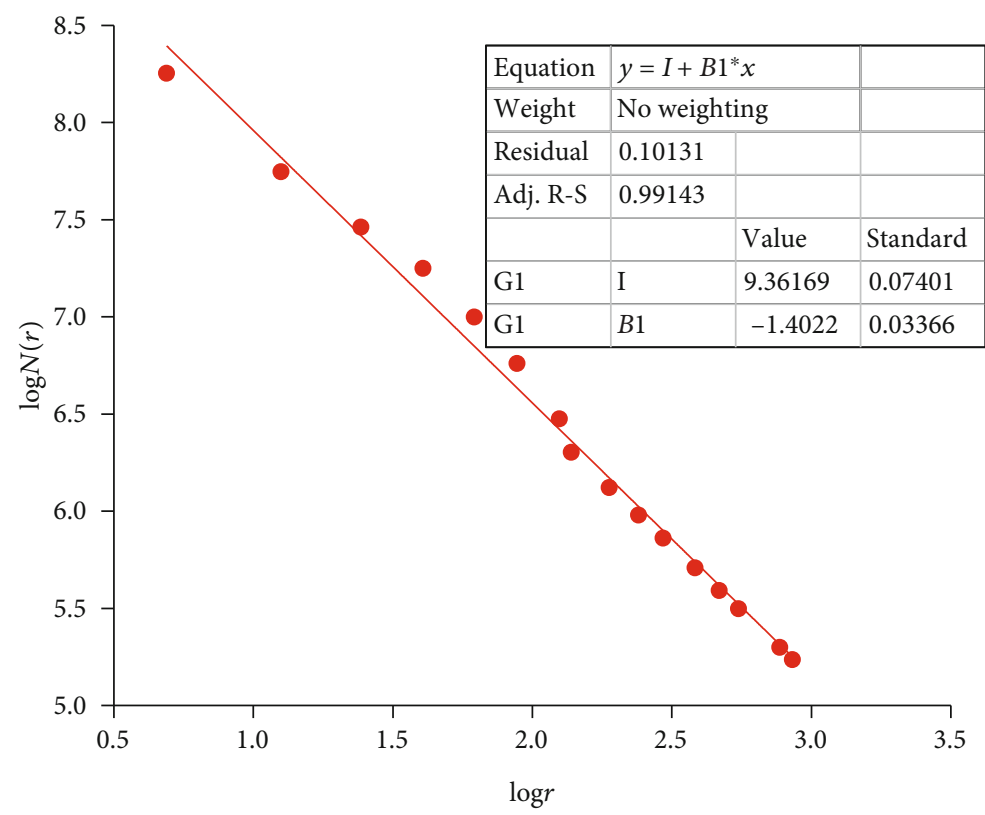

(b) S2-3

FIgURE 11: Continued. 


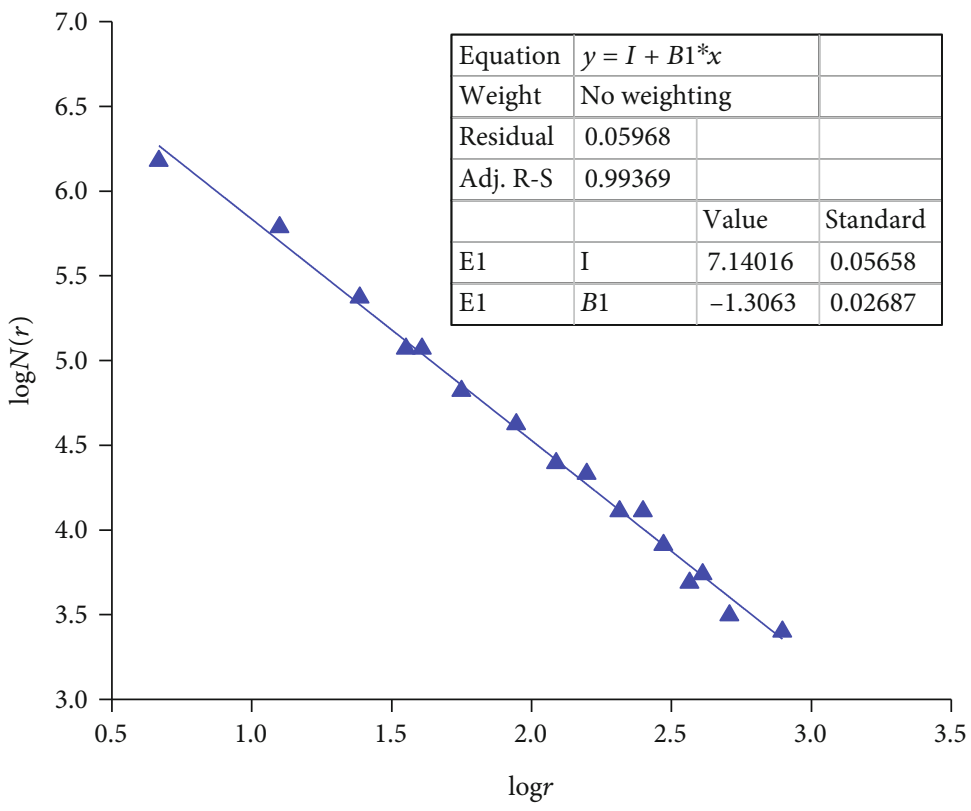

(c) $\mathrm{S} 3-2$

Figure 11: The fractal dimension of the final fracture surfaces.

simpler than that of the intact specimen. Based on the selfsimilarity of the fractal method, the test results can be applied to actual engineering laws, ensuring the feasibility of indoor testing.

\section{Conclusion}

In this paper, mechanical experiments and theoretical analysis are carried out to investigate the effect of the location of a joint with a $30^{\circ}$ inclination on the fracture failure characteristics of sandstone under natural moisture conditions. The main conclusions are as follows:

(1) The peak strength of sandstone with a joint in the middle is weakened and decreased by $22.67 \%$, compared with that of the sandstone with a joint at the bottom. The residual strength of a sandstone specimen with a joint plane in the middle is 1.4 times that of a sandstone specimen with a joint plane at the bottom. The lateral deformation is significantly affected by the joint location

(2) The location of the joint interferes with the fracture evolution and failure mode of the sandstone. The fracture of sandstone with a joint in the middle starts from the position of the joint, propagates far from the joint, then expands and tears, and finally results in a combined failure mode of shear failure across the joint and splitting failure. The fracture of sandstone with a joint at the bottom initiates at the lower end and propagates to the other side, which finally leads to shear failure across the joint surface

(3) The fracture fractal dimensions of sandstone with different joint locations are obtained based on fractal theory. Due to its self-similarity, the laws of fracture development and destruction in sandstone-containing joints in different locations can provide a theoretical basis for predicting the instability and failure of roadway surrounding rock in underground mining engineering

\section{Data Availability}

All data used to support the study are included within the article. 


\section{Conflicts of Interest}

The authors declare that there is no conflict of interest regarding the publication of this paper.

\section{Acknowledgments}

This work was supported by the National Natural Science Foundation of China (Grant Nos. 51474120 and 51974148).

\section{References}

[1] Y. Li, J. Oh, R. Mitra, and I. Canbulat, "A fractal model for the shear behaviour of large-scale opened rock joints," Rock Mechanics and Rock Engineering, vol. 50, no. 1, pp. 67-79, 2017.

[2] Y. L. Zhao, L. Zhang, W. Wang, C. Pu, W. Wan, and J. Tang, "Cracking and stress-strain behavior of rock-like material containing two flaws under uniaxial compression," Rock Mechanics and Rock Engineering, vol. 49, no. 7, pp. 2665-2687, 2016.

[3] P. T. Wang, M. Cai, F. Ren, C. Li, and T. Yang, "A digital image-based discrete fracture network model and its numerical investigation of direct shear tests," Rock Mechanics and Rock Engineering, vol. 50, no. 7, pp. 1801-1816, 2017.

[4] M. Laghaei, A. Baghbanan, H. Hashemolhosseini, and M. Dehghanipoodeh, "Numerical determination of deformability and strength of 3D fractured rock mass," International Journal of Rock Mechanics And Mining Sciences, vol. 110, pp. 246-256, 2018.

[5] H. Mohammadi and S. Pietruszczak, "Description of damage process in fractured rocks," International Journal of Rock Mechanics and Mining Sciences, vol. 113, pp. 295-302, 2019.

[6] A. Bobet, "The initiation of secondary cracks in compression," Engineering Fracture Mechanics, vol. 66, no. 2, pp. 187-219, 2000.

[7] B. Gong, C. A. Tang, and S. Y. Wang, "Simulation of the nonlinear mechanical behaviors of jointed rock masses based on the improved discontinuous deformation and displacement method," International Journal of Rock Mechanics and Mining Sciences, vol. 122, p. 104076, 2019.

[8] R. H. Cao, R. B. Yao, and J. J. Meng, "Failure mechanism of non-persistent jointed rock-like specimens under uniaxial loading: laboratory testing," International Journal of Rock Mechanics and Mining Sciences, vol. 132, p. 104341, 2020.

[9] D. Y. Han, K. H. Li, and J. J. Meng, "Evolution of nonlinear elasticity and crack damage of rock joint under cyclic tension," International Journal of Rock Mechanics and Mining Sciences, vol. 128, p. 104286, 2020.

[10] Z. C. Tang, C. C. Xia, Y. Y. Jiao, and L. N. Y. Wong, "Closure model with asperity interaction in normal contact for rock joint," International Journal of Rock Mechanics and Mining Sciences, vol. 83, pp. 170-173, 2016.

[11] Y. L. Zhao, Y. X. Wang, W. Wang, L. Tang, Q. Liu, and G. Cheng, "Modeling of rheological fracture behavior of rock cracks subjected to hydraulic pressure and far field stresses," Theoretical and Applied Fracture Mechanics, vol. 101, pp. 5966, 2019.

[12] Y. L. Zhao, L. Zhang, J. Liao, W. Wang, Q. Liu, and L. Tang, "Experimental study of fracture toughness and subcritical crack growth of three rocks under different environments," International Journal of Geomechanics, vol. 20, no. 8, p. $04020128,2020$.
[13] C.-C. Chiu, M.-C. Weng, and T.-H. Huang, "Modeling rock joint behavior using a rough-joint model," International Journal of Rock Mechanics and Mining Sciences, vol. 89, pp. 14-25, 2016.

[14] Y. Liu and F. Dai, "A damage constitutive model for intermittent jointed rocks under cyclic uniaxial compression," International Journal of Rock Mechanics and Mining Sciences, vol. 103, pp. 289-301, 2018.

[15] Q. Zheng, E. Liu, P. Sun, M. Liu, and D. Yu, "Dynamic and damage properties of artificial jointed rock samples subjected to cyclic triaxial loading at various frequencies," International Journal of Rock Mechanics and Mining Sciences, vol. 128, pp. 101-121, 2020.

[16] Y. Liu, F. Dai, P. Fan, N. Xu, and L. Dong, "Experimental investigation of the influence of joint geometric configurations on the mechanical properties of intermittent jointed rock models under cyclic uniaxial compression," Rock Mechanics and Rock Engineering, vol. 50, no. 6, pp. 1453-1471, 2017.

[17] Z.-Y. Yang, A. Taghichian, and G.-D. Huang, "On the applicability of self-affinity concept in scale of three-dimensional rock joints," International Journal of Rock Mechanics and Mining Sciences, vol. 48, no. 7, pp. 1173-1187, 2011.

[18] A. Fathi, Z. Moradian, P. Rivard, and G. Ballivy, "Shear mechanism of rock joints under pre-peak cyclic loading condition," International Journal of Rock Mechanics and Mining Sciences, vol. 83, pp. 197-210, 2016.

[19] Y. C. Zhang, Y. Jiang, D. Asahina, and C. Wang, "Experimental and numerical investigation on shear failure behavior of rock-like samples containing multiple non-persistent joints," Rock Mechanics and Rock Engineering, vol. 53, no. 10, pp. 4717-4744, 2020.

[20] F. Johansson, "Influence of scale and matedness on the peak shear strength of fresh, unweathered rock joints," International Journal of Rock Mechanics and Mining Sciences, vol. 82, pp. 36-47, 2016.

[21] Z. C. Tang, Y. Y. Jiao, L. N. Y. Wong, and X. C. Wang, "Choosing appropriate parameters for developing empirical shear strength criterion of rock joint: review and new insights," Rock Mechanics and Rock Engineering, vol. 49, no. 11, pp. 44794490, 2016.

[22] Y. L. Zhao, L. Y. Zhang, and W. J. Wang, "Experimental study on shear behavior and a revised shear strength model for infilled rock joints," International Journal of Geomechanics, vol. 20, no. 9, p. 04020141, 2020.

[23] D. Y. Han, J. Zhu, and Y. F. Leung, "Deformation of healed rock joints under tension: experimental study and empirical model," Rock Mechanics and Rock Engineering, vol. 53, no. 7, pp. 3353-3362, 2020.

[24] L. Y. Zhang, "Estimating the strength of jointed rock masses," Rock Mechanics and Rock Engineering, vol. 43, no. 4, pp. 391402, 2010.

[25] N. Barton, "Review of a new shear strength criterion for rock joints," International Journal of Rock Mechanics and Mining Sciences \& Geomechanics Abstracts, vol. 11, no. 11, pp. A220-A332, 1974.

[26] H. Shin and J. C. Santamarina, "An implicit joint-continuum model for the hydro-mechanical analysis of fractured rock masses," International Journal of Rock Mechanics and Mining Sciences, vol. 119, pp. 140-148, 2019.

[27] L. N. Y. Wong, D. Li, and G. Liu, "Experimental studies on permeability of intact and singly jointed meta-sedimentary rocks 
under confining pressure," Rock Mechanics and Rock Engineering, vol. 46, no. 1, pp. 107-121, 2013.

[28] Z. Y. Yang, J. M. Chen, and T. H. Huang, "Effect of joint sets on the strength and deformation of rock mass models," International Journal of Rock Mechanics and Mining Sciences, vol. 35, no. 1, pp. 75-84, 1998.

[29] T. H. HUANG, C. S. CHANG, and Z. F. YANG, "Elastic moduli for fractured rock mass," Rock Mechanics and Rock Engineering, vol. 28, no. 3, pp. 135-144, 1995.

[30] J. Arzúa, L. R. Alejano, and G. Walton, "Strength and dilation of jointed granite specimens in servo-controlled triaxial tests," International Journal of Rock Mechanics and Mining Sciences, vol. 69, pp. 93-104, 2014.

[31] C. M. Gerrard, "Elastic models of rock masses having one, two and three sets of joints," International Journal of Rock Mechanics and Mining Sciences and Geomechanics Abstracts, vol. 19, pp. 15-23, 1982.

[32] T. T. WANG and T. H. HUANG, "A constitutive model for the deformation of a rock mass containing sets of ubiquitous joints," International Journal of Rock Mechanics and Mining Sciences, vol. 46, no. 3, pp. 521-530, 2009.

[33] B. Li, Y. Jiang, T. Mizokami, K. Ikusada, and Y. Mitani, "Anisotropic shear behavior of closely jointed rock masses," International Journal of Rock Mechanics and Mining Sciences, vol. 71, pp. 258-271, 2014.

[34] D. Yu, E. Liu, P. Sun, B. Xiang, and Q. Zheng, "Mechanical properties and binary-medium constitutive model for semithrough jointed mudstone samples," International Journal of Rock Mechanics and Mining Sciences, vol. 132, p. 104376, 2020.

[35] A. Ghazvinian and M. R. Hadei, "Effect of discontinuity orientation and confinement on the strength of jointed anisotropic rocks," International Journal of Rock Mechanics and Mining Sciences, vol. 55, pp. 117-124, 2012.

[36] X. X. Yang, H. W. Jing, C. A. Tang, and S. Q. Yang, "Effect of parallel joint interaction on mechanical behavior of jointed rock mass models," International Journal of Rock Mechanics and Mining Sciences, vol. 92, pp. 40-53, 2017.

[37] H. Yang, J. Liu, and B. Liu, "Investigation on the cracking character of jointed rock mass beneath TBM disc cutter," Rock Mechanics and Rock Engineering, vol. 51, no. 4, pp. 12631277, 2018.

[38] Z. H. Zhao, T. Guo, S. Li, W. Wu, Q. Yang, and S. Chen, "Effects of joint surface roughness and orientational anisotropy on characteristics of excavation damage zone in jointed rocks," International Journal of Rock Mechanics and Mining Sciences, vol. 128, p. 104265, 2020.

[39] Z. C. Tang and L. N. Y. Wong, "New criterion for evaluating the peak shear strength of rock joints under different contact states," Rock Mechanics and Rock Engineering, vol. 49, no. 4, pp. 1191-1199, 2016.

[40] Y. L. Zhao, Q. Liu, G. Tong, J. Tang, and S. Xie, "Deformation and energy dissipation characteristics of joints under cyclic confinements," Geotechnical and Geological Engineering, vol. 37, no. 6, pp. 5315-5325, 2019.

[41] S. Q. Yang, P. F. Yin, Y. C. Zhang et al., "Failure behavior and crack evolution mechanism of a non-persistent jointed rock mass containing a circular hole," International Journal of Rock Mechanics and Mining Sciences, vol. 114, pp. 101-121, 2019.

[42] Q. X. Meng, H. L. Wang, W. Y. Xu, and Y. L. Chen, "Numerical homogenization study on the effects of columnar jointed structure on the mechanical properties of rock mass," Interna- tional Journal of Rock Mechanics and Mining Sciences, vol. 124, p. 104127, 2019.

[43] K. Zhang, P. Cao, J. Meng, K. Li, and W. Fan, "Modeling the progressive failure of jointed rock slope using fracture mechanics and the strength reduction method," Rock Mechanics and Rock Engineering, vol. 48, no. 2, pp. 771-785, 2015.

[44] A. Stavrou and W. Murphy, "Quantifying the effects of scale and heterogeneity on the confined strength of micro-defected rocks," International Journal of Rock Mechanics and Mining Sciences, vol. 102, pp. 131-143, 2018.

[45] Y. C. Li, S. Sun, and C.'. Tang, "Analytical prediction of the shear behaviour of rock joints with quantified waviness and unevenness through wavelet analysis," Rock Mechanics and Rock Engineering, vol. 52, no. 10, pp. 3645-3657, 2019.

[46] P. L. P. Wasantha, P. G. Ranjith, D. R. Viete, and L. Luo, "Influence of the geometry of partially-spanning joints on the uniaxial compressive strength of rock," International Journal of Rock Mechanics and Mining Sciences, vol. 50, pp. 140-146, 2012.

[47] Q. L. Yu, S. Q. Yang, and P. G. Ranjith, "Numerical modeling of jointed rock under compressive loading using X-ray computerized tomography," Rock Mechanics and Rock Engineering, vol. 49, no. 3, pp. 877-891, 2016.

[48] J. D. Chen, S. P. Ma, and S. J. Liu, “An experimental study of the failure process of en-echelon fault structure using the digital speckle correlation method," vol. 48, no. 6, pp. 1416-1422, 2005.

[49] P. Yin, R. H. C. Wong, and K. T. Chau, "Coalescence of two parallel pre-existing surface cracks in granite," International Journal of Rock Mechanics and Mining Sciences, vol. 68, pp. 66-84, 2014.

[50] M. N. Bagde, A. K. Raina, A. K. Chakraborty, and J. L. Jethwa, "Rock mass characterization by fractal dimension," Engineering Geology, vol. 63, no. 1-2, pp. 141-155, 2002.

[51] Y. D. Wang, W. Dan, Y. Xu, and Y. Xi, "Fractal and morphological characteristics of single marble particle crushing in uniaxial compression tests," Advances in Materials Science and Engineering, vol. 2015, 10 pages, 2015.

[52] Y. Deng, M. Chen, Y. Jin, and D. Zou, "Theoretical analysis and experimental research on the energy dissipation of rock crushing based on fractal theory," Journal of Natural Gas Science and Engineering, vol. 33, pp. 231-239, 2016.

[53] Y. Li and R. Huang, "Relationship between joint roughness coefficient and fractal dimension of rock fracture surfaces," International Journal of Rock Mechanics and Mining Sciences, vol. 75, pp. 15-22, 2015.

[54] M. M. He, Z. Zhang, J. Zheng, F. Chen, and N. Li, "A new perspective on the constant mi of the Hoek-Brown failure criterion and a new model for determining the residual strength of rock," Rock Mechanics and Rock Engineering, vol. 53, no. 9, pp. 3953-3967, 2020. 